\title{
SHEA Membership Soars
}

In the past 24 months, membership has climbed by $60 \%$, from 501 to 801 . This rapid growth has paralleled the rapid expansion of the Society's activities after it took on professional management in 1990. There are now SHEA members in 48 states, Puerto Rico, and the District of Columbia. SHEA has 64 members in 17 foreign countries. Of the members from outside the United States, 29 are from seven provinces in Canada.

The majority of our members hold MD or DO degrees; 25 members are PhDs. The bylaws require that applicants for membership hold a doctoral degree and work in the field of hospital epidemiology. In addition to receiving our official journal, Infection Control and Hospital
Epidemiology, and our quarterly SHEA Newsletter, members receive a $\$ 50$ discount on registration at the Annual Meeting.

At $\$ 85$ per year, membership continues to be a bargain, as well as an opportunity to network with those most active in the field of hospital epidemiology. Associate membership, at a reduced rate, is also available for fellows training in the field of hospital epidemiology. We invite eligible candidates for membership or associate membership to apply for membership using the application form published in each issue of Infection Control and Hospital Epidemiology.

\section{SHEA Position Pa er-Working Group Seeks Your I nput}

Loreen A. Herwaldt, MD, who chairs the working group on the role and dilemmas of the hospital epidemiologist, envisions a practical document that would address the "nuts and bolts" issues rather than the principles of hospital epidemiology. They anticipate publishing it as a pamphlet and also as a series of articles in Infection Control and Hospital Epidemiology. If you would like to suggest topics or volunteer to write a section, please contact Dr. Herwaldt, Academic Councilor, FAX (319) 3563086.

\section{SHEA Annual Meeting Update -- Late Breaker Session}

Four abstracts have been accepted for presentation at the late breaker session on Monday, April 19, 1993, at 5:15 PM at the Third Annual Meeting of SHEA at the Palmer House in Chicago (April 1820, 1993).

1. The Utilization of Severity Indexes in Intensive Therapy as a Predictor of $\mathrm{N}$ osocomial Infection Risk: TISS versus ASIS. Starling CEF, Pinto CAG, Pinheiro SMC, Nogueira MG, Couto BRGM. Felicio Rocho Hospital, Belo Horizonte, Minas Gerais, Brazil.

2. The Effect of Influenza $V$ accination on Sick Leave A mong Hospital Employees. Edmond M, Wenzel RP, Yank T, Doebbeling B.
The University of Iowa College of Medicine, University of Iowa Hospitals and Clinics, Iowa City, Iowa.

3. Product $V$ ariance in PPD

Positivity Rate. Fauerbach LL, Boeff D, Shands JW, Gutekunst RR. The University of Florida and the Shands Hospital at the University of Florida, Gainesville, Florida.

4. The Impact of HEPA Filtration on Airborne Particulates

Brief items of interest for the SHEA N ews or N ewsletter may be sent to C. Glen Mayhall, M D, SHEA, N ewsletter Editor, Division of Infectious $D$ iseases, D epartment of $M$ edicine, U niversity of Tennessee, M emphis, 956 Court A ve., M emphis, TN 38163; FAX (901) 528-5854. Copy should be typed, doublespaced, and should not exceed five pages. 